\title{
Teaching a thorough, repeatable design process for ambiances in architecture
}

\author{
Thomas M. Lesko ${ }^{1}$ \\ ${ }^{1}$ College of Architecture, Design and Management, Wentworth Institute of Technology
}

\begin{abstract}
Le Corbusier, it has been said, defined architecture as "the poetry of construction" and as such, the term "ambiances" is reminiscent of those great words. In order to create that special quality, that poetry, that ambiance in architecture, a design concept that is the result of a thorough, repeatable design process must be employed. The purpose of this paper/presentation is to explain the design thinking/design tools we need to teach our students, i.e. the future Le Corbusiers of the world, how to create those special qualities that make ambiances/poetry in architecture possible.
\end{abstract}

A design process for architecture, or other design fields for that matter, begins with seeking a full understanding of the problem, which can be broken down into several identifiable and teachable aspects, and ends with the generation of viable and defendable design alternatives. A study of the processes utilized by great architects shows that each goes through a similar process, one that begins with steps that define all facets of the problem, including context, program and client issues.

Several cases in point will be used in this paper that illustrate, by professional examples, what great architects do regarding process to create the beautiful ambiances inherent in their artistic creations. For this paper, selected works by Herzog and de Meuron and by Renzo Piano will be used; these are architects that students normally have a familiarity with. I chose these selected projects because of the "perceived" difficulties that each problem presented. Those difficulties can become poetry of course... problems are most often opportunities for design expression. How does one design poetry into a simple warehouse on the site of a former rock quarry?

Herzog and de Meuron, when they created the wonderful buildings for Ricola, in Laufen, Switzerland, found the special "design generating" data that helped them design buildings having that special quality. The design process that they utilize seeks out those important elements of ambiance-related, ambiance generating knowledge. 


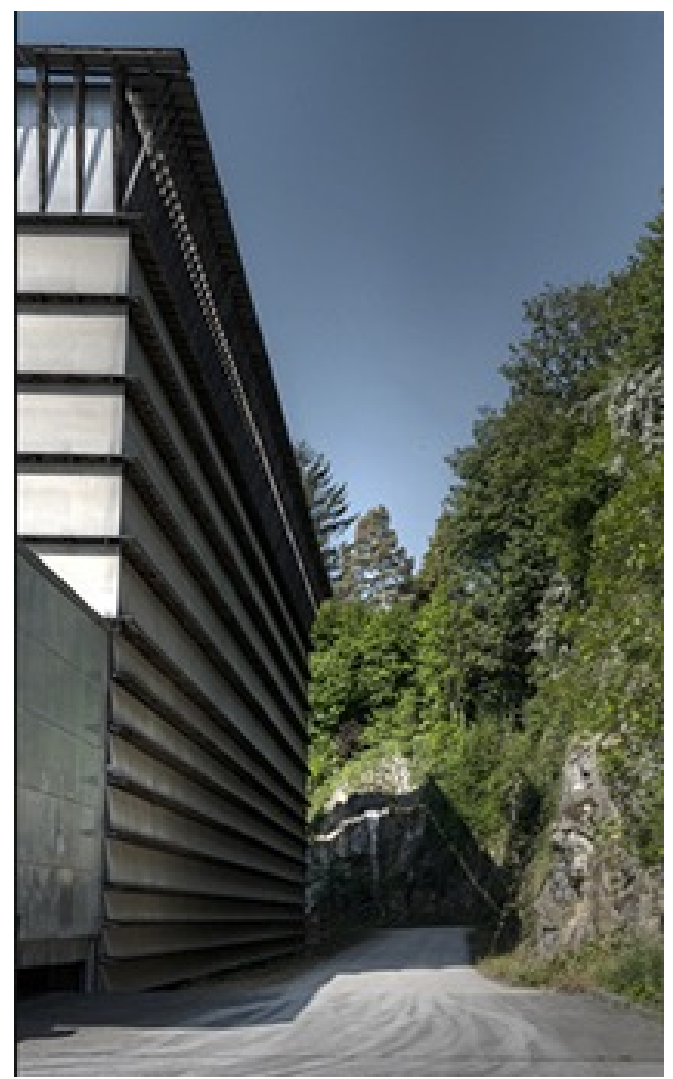

Fig. 1. Herzog and de Meuron, Ricola Warehouse, Laufen, Switzerland

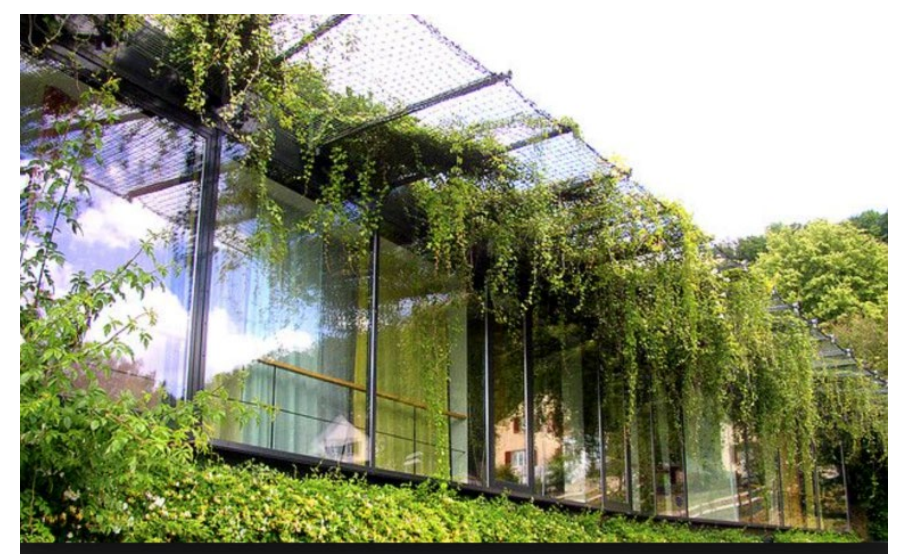

Fig. 2. Herzog and de Meuron, Ricola Marketing Building, Laufen, Switzerland

Renzo Piano finds the special ambiance-related elements of his projects by utilizing a design process that also seeks out those special pieces of information. How does one design poetry in an urban context, when it is necessary to extend the work of another great architect? In the expansion of the High Museum of Art in Atlanta, Piano had to deal with an existing context that was not only the work of Richard Meier, who designed the original museum, but also surrounding buildings of performance art and art studios. 
These are both situations that students can relate to because they struggle to understand the problems given to them just as these examples are difficult to see where the poetry can come from.

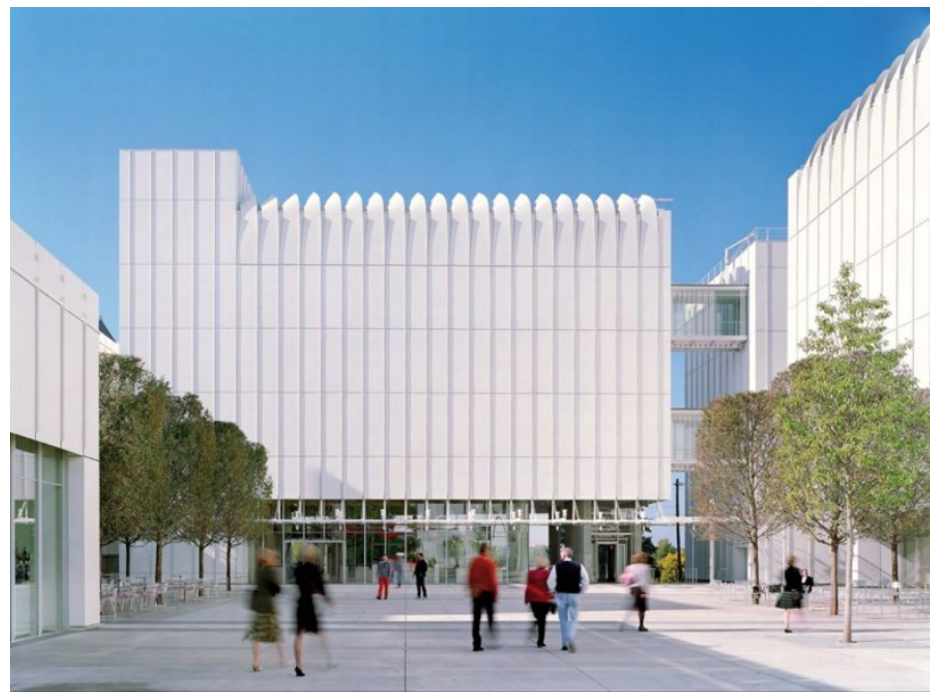

Fig. 3. Renzo Piano, High Museum Expansion, Atlanta, GA

Each of these examples presented an unusually difficult challenge for the designers. To be most valuable to students, one must show 'how' they were able to be successful and 'where' the design inspirations came from. Doing this provides the invaluable tools that form a solid process for design and serve to illustrate just what great architecture in the twenty first century.

\section{Definition of Architecture and Abstraction}

It is important to define architecture in words that are not arbitrary opinion statements. To that end, I state that architecture is an abstract visual representation of elements of context and elements of program. Moreover, it is also necessary to state in a non-arbitrary opinion statement what abstraction is. Abstraction is the removal of blatant, obvious visual information so that more information and meaning can be included. One does not need an entire tree to communicate what the essence of the tree is.

This presentation gives students the tools to do that work, presented in a definable, teachable, eight-step design process that yields poetry. . . ambiances in architecture.

\subsection{Step one: Background and Context Data Collection}

Problem-"seeking" is a valuable term in the studio context because it not only defines a necessary part of a design process, but it also raises awareness to the fact that when a problem is presented to students and architects, it is not the complete problem. There are multiple facets to each and every problem, and they all need to be defined and explored. Each and every piece of a problem holds design ambiance generating potential. 
Along with an initial familiarization of the problem, an initial familiarization with the context provides an overall picture of where the design will be located. This is an invaluable "stepping into" the problem step, without putting pressure on a student to come up with initial evaluations, students can allow their senses and intuitions regarding the context to come into play. Every project must begin at some point; typically, students will begin by reading the project statement given by the professor, visiting the site, taking pictures and gathering site/contextual information that will be put onto a site plan in no organized fashion, but perhaps with some good graphics to make it look the part. This is a start, but hardly an analysis or good background. A project background statement should explain the origins of the problem in detail, the desires of the client and any information that is available to the problem at the beginning of the process, drawing on data collected and organized well.

\subsubsection{Data Collection}

Once familiar with the context and once the problem has been defined in full, more detail is sought. Providing seventeen different categories for data collection, with some prodding descriptions to get students to think through each, provides a great frame for this segment. Not to be confused with what some call "site analysis", a thorough collection of context data provides the opportunity for students to fully understand the context and subsequent idea generating potential of each category of data.

Context analysis is a two-part process: the collection and organization of data into distinct categories and the subsequent analysis of the data. The data analysis can take the form of a design idea generated by those data or can be an answer to the question "so what?". So what could the data mean to the problem? How could it be utilized? Is it a good thing or a bad thing?

The site and its context should be analyzed by first collecting data, and then, in a separate step, analyzing those data, an often misunderstood or omitted step. Data should be collected in at least the following categories: history, site location, site size, site legalities, physical neighborhood, sun direction, movement and effect on the site, existing vegetation, topography and drainage, built elements found on the existing site, pedestrian circulation, vehicular circulation, noise, views from, to and through the site, and human, cultural and social elements relating to the site. [1] The information found in those categories should be organized, and then, in a separate step, responded to with words and sketches of analysis.

\subsection{Step Two: Context Data Analysis}

Typically, students are asked to use one sheet of paper for each category above. This acts as an organizing element. The paper is divided into two parts, the top has a small picture or sketch of the site and the bottom also has the same picture or site sketch. The top is where the data is placed, relating to the site with arrows or other graphics. The bottom is where the "responses" go. This is the analysis. Without some response to the data, there is no analysis. The results from a pool of ideas from which the concept may be drawn. Because this produces many pages of well-organized information and analysis, an overview is written for the actual concept statement. The following is the example sheet I give to students: 


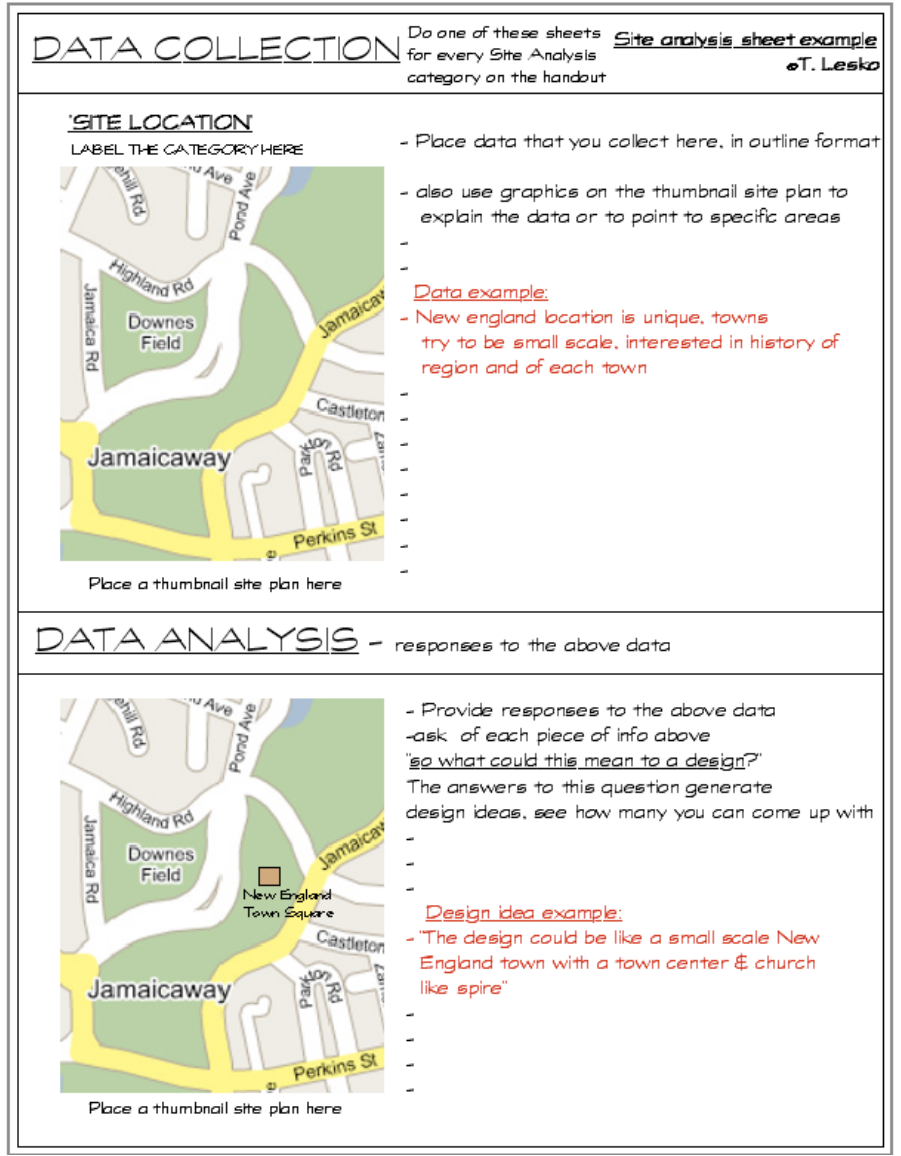

Fig. 4. Context Data Collection and Analysis

As mentioned, some professors advise students to do a "site analysis" that only consists of information gathering and perhaps a graphic site plan with information on that plan. Unfortunately, with that approach, there is little analysis done. It is with meaningful analysis that idea generation in its full glory can be accomplished - searching for ideas with the potential for the creation of the poetry of construction, as Corbu would say. With pages of data collected, there is one key to idea generation and creating design alternatives from the context. That key is to ask "So what" of the data. So what... does it mean? So what... 'could' it mean? With words and necessary thumbnail sketches, literally dozens of ideas will be generated and the search for the ambiances that make great architecture is easily accomplished.

\subsubsection{Design ideas from the context}

With an abundance of design ideas, some method of judgement needs to be employed. What is most important? What is yielding the most excitement? What satisfies the designer's artistic imagination? Qualitative and quantitative questioning the ideas by the designer, from both contextual analysis and program/problem analysis, one can simply state design goals. The stating of design goals clarifies the design direction and moves toward the clear statement of a solid, meaningful concept statement. 


\subsection{Step Three: Idea generation - creating design ideas from the problem:}

With the belief that great architecture in the twenty-first century is an abstract expression of context and program, there needs to be a phase where the program is "mined" for architectural expression. In each program, there exist important elements or qualities that can be discerned from the others. Searching for these "profound qualities" is the step required to move toward a series of working concept ideas. For example, the Ricola warehouse, was to be... a place to stack and store the products of the company. By itself, this does not sound profound, however, if seen through the lens of poetry and ambiance, a profound quality was stated and explored. How can storage and stacking of product be artistic? A patient search yielded the result.

With each design problem, we must be able to find and state some 'profound' or otherwise 'special' quality to build a concept around. These qualities will be found in the following categories:

- site/background analysis,

- the particular user or client,

- the project.

These qualities should be stated clearly, elaborated on, and will be part of the decision process to develop a concept. Here is an example of stating a profound quality by Terrence Harkness. It is in reference to a project to design a garden in the relatively flat land of Illinois. This example is used because students initially see little to build a concept upon - the land is flat farmland, and little is seen initially to work with. It provides a good example of what can be done with apparently little.

"Living in the Middle West (of the U.S.) and experiencing it's particular light, the expanse of sky and horizon and the effect of sunset on the flat plane of farm lands - these have been particularly powerful components of my visual sense. During the summer, impressions of changing field patterns have provided experience in spaciousness, incised pattern and exploration..."important qualities present in the landscape of east central Illinois: the richness and detail of winter trees, for example, seen against the sky. Ground fog of late fall shrouds the intermittent lines of hedgerows."[2]

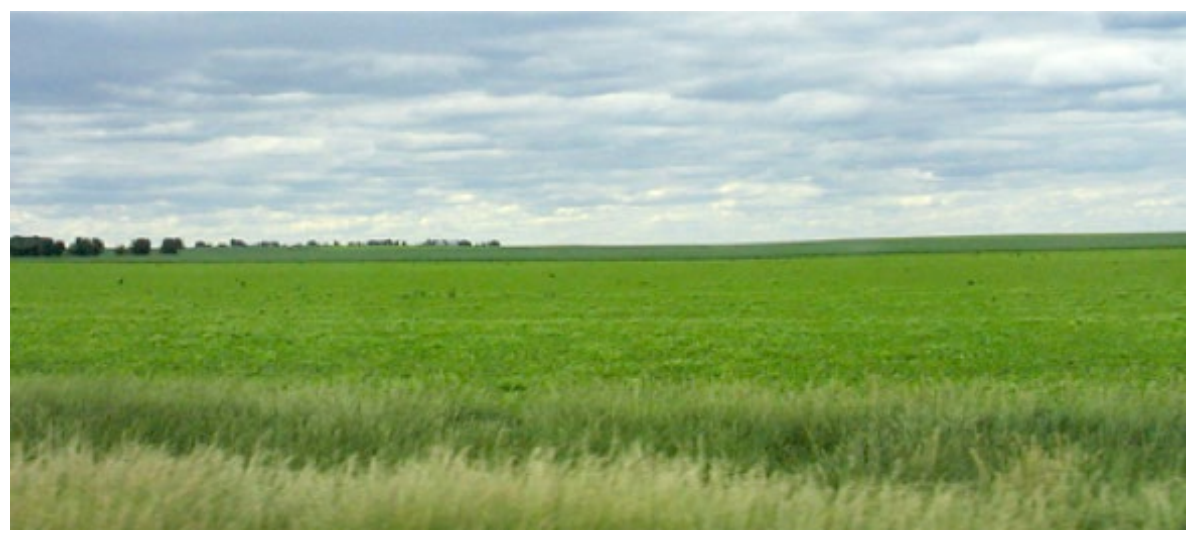

Fig. 5. Site Image 
Sketches were made to explore the qualities presented and to translate the written qualities into graphic images which can be used to form design ideas. The translation of written words into visual images is a most important step in design. And it is addressed after the concept pyramid is created. These sketches take the first steps into that translation.

Fig. 6. Site Sketch A (Harkness)

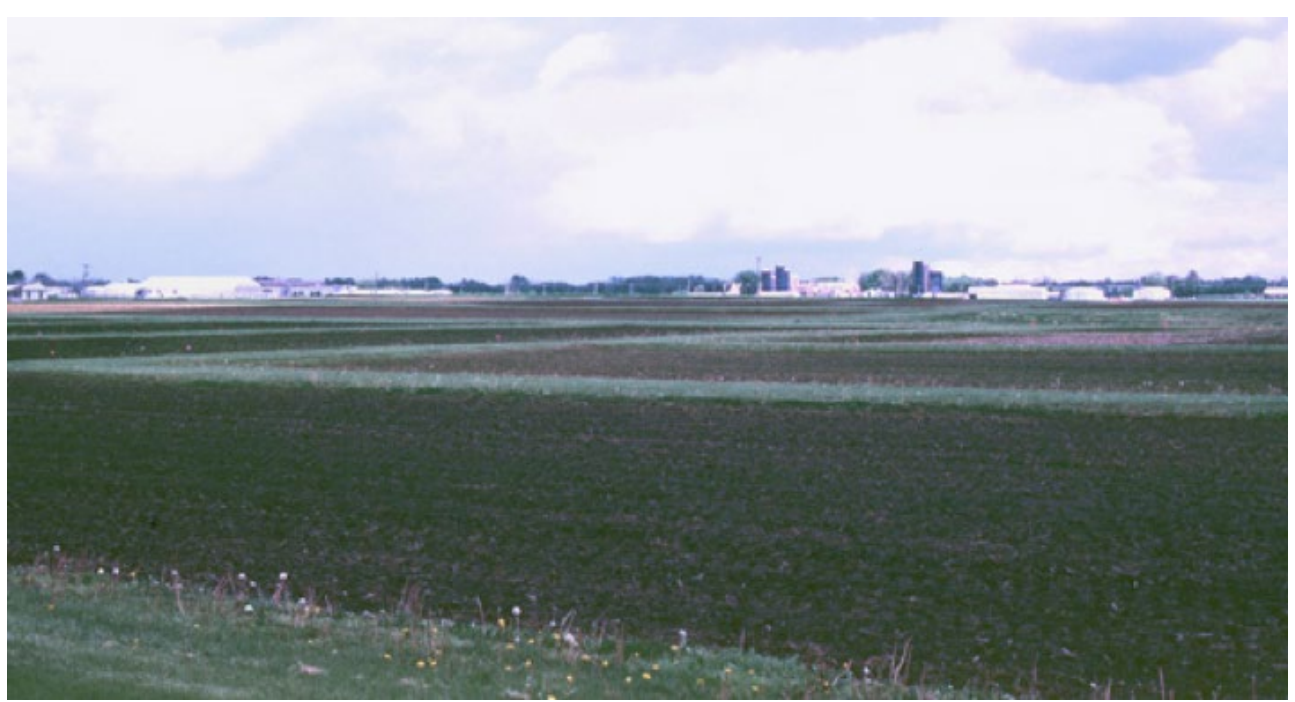

Fig. 7. Site Image B (Harkness) 




Fig. 8. Site Ariel Photo (Harkness)
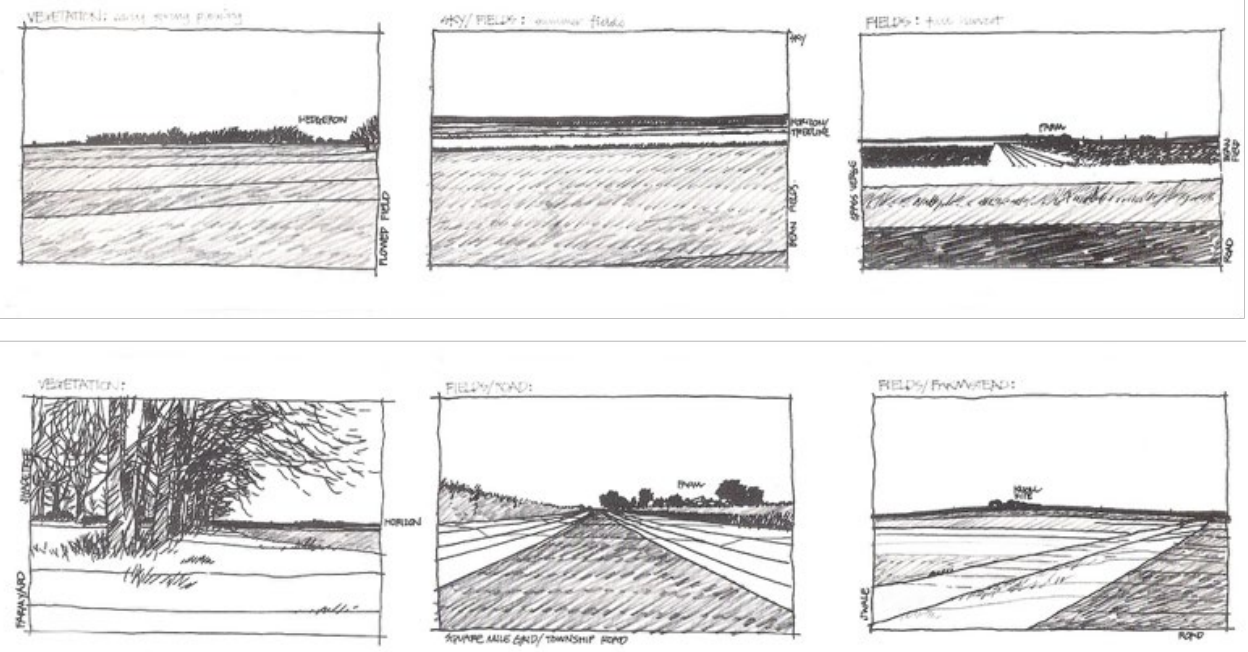

Fig. 9. Site Interpretation Sketches (Harkness)

\subsection{Step Four: Expressing Personal Vision:}

Each designer possesses a background and personal vision that is unique. It is important that students understand this and are able to make some statement about what they love... what captivates them regarding the design that they are about to create. If they have trouble stating this, it serves as a reminder that this is something missing from their development and must be addressed. This uniqueness is what makes a design wonderful and personal. An example of this kind of statement for the above garden design:

"One's vision of the world is part of the feeling behind - and subject of - much of one's work. This garden expresses my deep affection for the Illinois landscape. As expressed in 
this garden, the vision originates in the rural Middle West. The garden reflects my preoccupation with the visual qualities of these places, and my attempt to confirm and reveal them to others. Its creation has required a conscious acknowledgement of the importance and power of both past and current experience." [2]

\subsection{Step Five: Choosing a Design Direction:}

The information in steps 1, 2 and 3 provide the basis for a design concept. Once that is achieved, a design "direction" can be chosen. This is not a concept necessarily, but is identifying an area of interest. Students choose a "design direction" based on the important elements, and then explain how that choice comes from something in categories 1 and/or 2 above. They especially build on one of the profound or special qualities found above and describe it in a paragraph.

Words or themes must be identified that can be translated into some physical form. For example, if we were to design a "Fire Station", we could analyze the context and analyze the project, the building type and the clients... but we are still wondering: what will the fire station look like? What is its architectural statement, its concept?

Using the example of the Illinois garden, a design direction would involve the use of the unique landscape of that region, specifically the flatness of the fields, the looming horizon, the straightness of lines forming roads, fields and fences as explored in the sketches. These elements are periodically punctuated by intersections where trees, houses, barns and silos exist. The choice of dealing with these elements defines a direction, and also defines elements that can be transformed into design elements - the verbal to written translation. A concept statement can now be formed.

\subsection{Step Six: Forming a Concept Title}

The concept title provides the beginning of and the ultimate "focus" for a concept, it sums up the concept in precious few words. By defining a title, a statement is made: "my design will be this". It may change, however: a stand must be taken! A decision must be made and subsequently explored to find its image. Here are two ways to write a concept title. Students define a very short title for their project using one of these methods:

\#1) The Simile/Metaphor method

- An example of a concept title using the "simile/metaphor" method using "As or Like" to start a concept title:

Concept Title Example:

"The Illinois Garden as a Regional Landscape" or

"The Illinois Garden like a Series of Regional Elements"

(I provide definitions for students who should but may not know what these are)

Simile: a figure of speech comparing two unlike things that is often introduced by like or as (as in: "cheeks like roses" )

Metaphor: a figure of speech in which a word or phrase literally denoting one kind of object or idea is used in place of another to suggest a likeness or analogy between them (e.g.: drowning in money). Moreover, metaphors are comparisons that show how two things that are not alike in most ways are similar in one important way. Metaphors are a way to describe something: "Cindy was such a mule. We couldn't get her to change her mind." 
\#2) The Title: subtitle method

- An example of a concept title using the "Title: subtitle" method:

Concept Title Example:

"An East Central Illinois Garden: A 'Regional' Garden"

\subsection{Step Seven: Defining Project/Design Goals}

The definition of project goals is a difficult one for students, however, providing them with a good example that they can compare their statement to is quite helpful. In reality, the actual concept statement is imbedded in this section. It is an elaboration of the concept title and is about the student's design direction, it is not about the program at this point. Again, using in part the Harkness project statement as a good example of a goals statement:

"The goal of the East Central Illinois garden is to recreate the extreme flatness of the landscape - the strong horizon, the essentially open and treeless terrain, the tension between the crispness of edge and the warping of the land plane... The patterns are seldom symmetrical but are all contained in the Jeffersonian square-mile grid." [2]

\subsection{Step Eight: Convey the Project's Purpose}

At this point, the purpose of the design should be stated. There are subtle differences between the goals above and the purpose. The purpose of the project is further elaboration of the concept title, but it also should include programmatic information. This combination of concept and program is an important junction, one that will be explored with design sketches and helps make that important leap from verbal information to graphic imaging.

"This garden's purpose is to reflect these characteristics (the profound qualities, referenced above, ed.) as a visible, built expression, to be experienced through time, seasons and changing light. The garden focuses on and celebrates the landscape; it should demonstrate the power and qualities of this unique place. The design sources for this garden are in the landscape itself. The garden and the landscape are inseparable." [2]

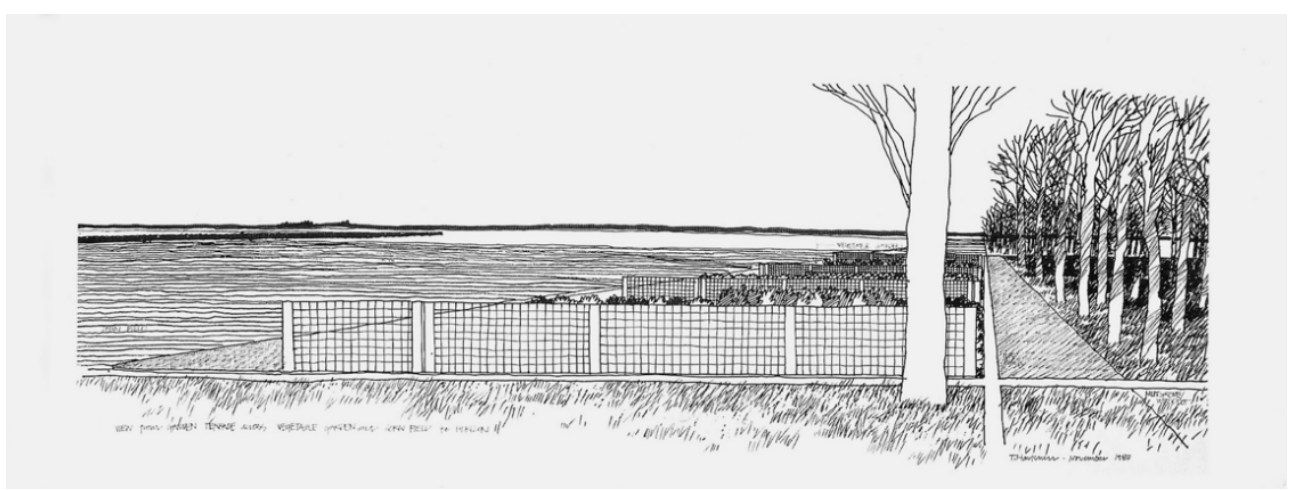

Fig. 10. Design Sketch A (Harkness) 


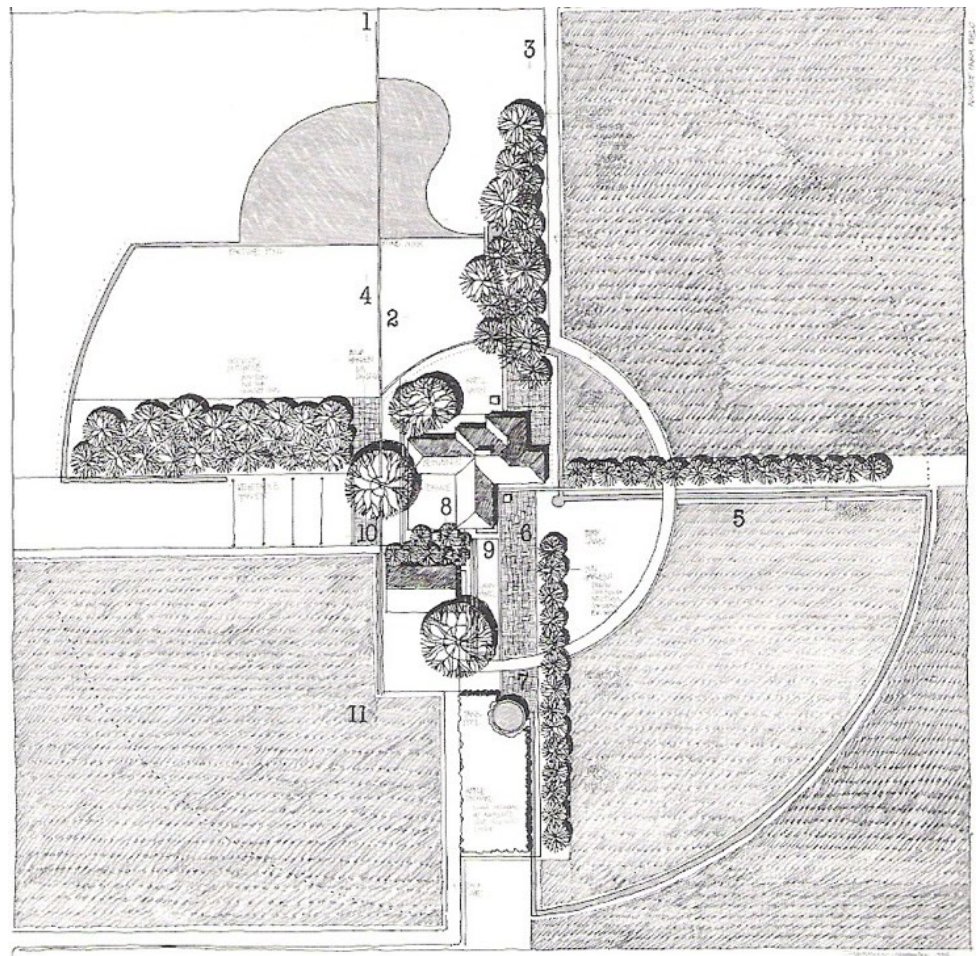

Fig. 11. Design Sketch B (Harkness)

The above steps are a definition of what steps designers go through to design. Based on the belief that architecture is not an arbitrary thing, that architecture is an abstract visual representation of elements of context and elements of program woven together with the art and skill of the individual pursuing personal vision and/or ideology. Moreover, that abstraction is the removal of blatant, obvious visual information so that more information and meaning can be included. It has been said that design is a patient search, so, now that the problem has been elaborated and ideas, goals and concepts have been identified, the search begins (continues?). The generation of alternatives - of possibilities that bring to life the ideas, goals and concepts defined is now the task at hand. If one believes that the work done to this point is valid, that it is correct and exciting, sketching possibilities of those things are the final part of the design process. The design process is identifiable and deliberate and illustrates that good design does not fall from the sky in a burst of light, it takes work. That patient search will yield countless possibilities for the creation of architectural poetry.

\section{References}

1. White, Edward T. Site Analysis. Architectural Media Ltd., 1983, Tucson, 1983, pg. 26. Print

2. Harkness, T.: 1986, "An East Central Illinois Garden," Transforming the American Garden: 12 New Landscape Designs, Cambridge, MA: Harvard University Graduate School of Design, Exhibit Brochure pg. 40 